\title{
Estimativa da infiltração da água em um solo de várzea através do mo- delo de green-ampt com ajustes de parâmetros
}

\author{
Estimation of water infiltration in a floodplain soil through the green-ampt model \\ with adjustment parameter
}

Wendler de Almeida Dockhorn, Virnei Silva Moreira, Silvana Maldaner, Jaqueline Prunzel, Vanessa Silva Moreira, Debora Regina Roberti

wendler.dockhorn@gmail.com; virneimoreira@gmail.com; silvana.maldaner@gmail.com; jaquelineprunzel@gmail.com; vanessaeng.ftal@gmail.com; debora@ufsm.br>

\begin{abstract}
Resumo
A necessidade de buscar um modelo que descreva o processo de infiltração da água no solo com maior aproximação a realidade, é extremamente importante, principalmente considerando as características físicas que um solo possui, pois o conhecimento desse processo é de fundamental importância para o manejo eficiente do solo e da água nos cultivos agrícolas. O presente trabalho tem como objetivo validar o modelo de Green-Ampt em uma área de cultivo de arroz. O experimento foi realizado no sítio experimental de Paraíso do Sul - RS, onde foram coletadas amostras do solo para análise física e utilizado o método de infiltrômetro de anéis para a obtenção dos valores da infiltração acumulada. Os resultados obtidos através do modelo de Green-Ampt não gerou resultados aceitáveis para aplicação. Com desenvolvimento do trabalho, conclui-se que, para a aplicação do modelo de Green-Ampt é necessário buscar uma nova proposta de ajuste de parâmetros que consiga descrever o processo de infiltração para o tipo de solo estudado.
\end{abstract}

Palavras-chave: Modelo Green-Ampt, infiltração, Cultivo de arroz.

\begin{abstract}
The need to find a model that describes the process of water infiltration into the soil which could be more closer to the reality is extremely important, especially considering the physical characteristics of a soil has, because a better understanding of this process is of fundamental importance for the efficient management of soil and water in agricultural crops. This study aims to validate the model of Green-Ampt in a rice-growing area. The experiment was conducted in the experimental site of Paraíso do Sul - RS, where soil samples were collected for physical analysis and used the double ring infiltrometer to obtain the values of cumulative infiltration. The results obtained through the Green-Ampt model did not generate acceptable results for application. With the development of the work, it was concluded that for the implementation of Green-Ampt model it is necessary to find a new parameter setting proposal that can describe the process of infiltration to the soil type studied.
\end{abstract}

Keywords: Green-Ampt model, infiltration, Cultivation of rice. 


\section{Introdução}

Na cultura do arroz irrigado o sistema de irrigação por inundação pode atingir $20 \%$ do custo total de produção, sendo considerado um dos fatores que mais contribui para onerar este sistema (da Silva Gomes e Pauletto, 1999). Por este motivo, é necessário considerar o balanço hídrico, que é onde se calcula todos os ganhos e perdas hídricas que ocorrem num local ou área, de modo a estabelecer a quantidade de água disponível em certo momento (Buriol, 2009). Sendo, um dos principais componentes do balanço hídrico, o processo de infiltração, que em casos de inundações, é um fator determinante da altura da lâmina d'água e do escoamento superficial. Portanto, o conhecimento desse processo é de fundamental importância para o manejo eficiente do solo e da água nos cultivos agrícolas (Reichardt e Timm, 2004).

Nesse contexto, é preciso buscar um modelo que descreva o processo de infiltração da água no solo com maior aproximação a realidade, considerando as características físicas que um solo de várzea possui e também possíveis imprevistos que possam interferir na capacidade de previsão do modelo.

Segundo dos Santos Brandão et al. (2006), as constantes dos modelos empíricos não possuem um significado físico, são obtidas através de um ajuste de curvas a partir dos dados obtidos em campo com o auxílio de um infiltrômetro e, são válidos apenas para as mesmas condições iniciais do momento da coleta, diferentemente dos modelos teóricos, como o de Green-Ampt, que é baseado na teoria física do escoamento em meios porosos.

Segundo de Mello (2003), os parâmetros da equação de Green-Ampt são de caráter físico e podem ser determinados a partir das propriedades físicas do solo. Entretanto, o fato desses parâmetros não representarem fielmente as condições reais de ocorrência da infiltração, fez com que diversos autores propusessem diferentes metodologias para determiná-los, a fim de melhorar a simulação feita com a utilização deste modelo.

Desta forma o presente trabalho tem como objetivo validar um modelo teórico com alguns ajustes de parâmetros, aplicados em um solo classificado como Planossolo Hidromórfico Distrófico em uma área de cultivo de arroz irrigado.

\section{Metodologia}

A coleta dos dados foi realizada em um solo classificado como Planossolo Hidromórfico Distrófico (EMBRAPA, 1999), no período de pousio em uma área destinada ao cultivo de arroz irrigado em um sítio experimental localizado na cidade de Paraíso do Sul (29044'39,6"S; $\left.53^{\circ} 8^{\prime} 59,8^{\prime \prime} \mathrm{W}\right)$, região central do estado do Rio Grande do Sul. Neste local tem-se cultivado arroz irrigado desde a década de 80 e é considerado área de várzea.

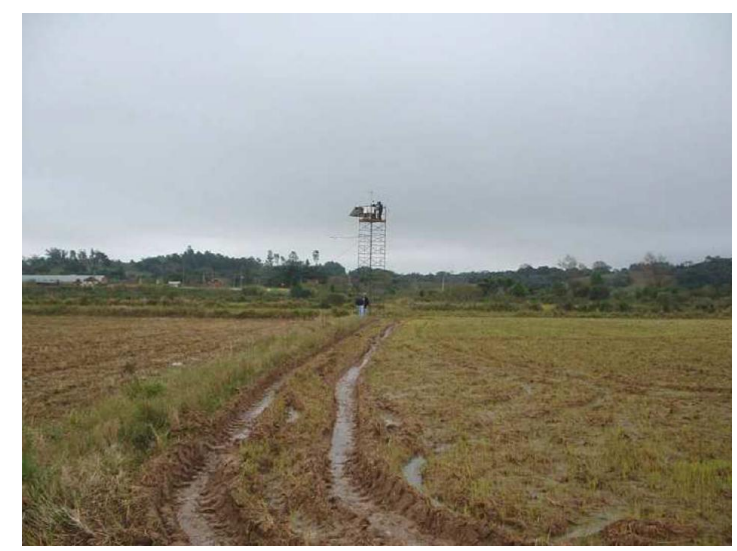

Figura 1: Foto do sítio experimental em Paraíso do Sul onde está localizada a área de cultivo de arroz que foi realizado o método de infiltrômetro de anéis e a coleta das amostras de solo para análise

As amostras do solo foram coletadas no sítio experimental e encaminhadas posteriormente ao Laboratório de Física e Hidrologia do Solo do Departamento de Solos da Universidade Federal de Santa Maria. A partir da análise laboratorial, determinaram-se os valores da granulometria, macroporosidade $\left(\phi_{\text {macro }}\right)$, porosidade total $(\phi)$, umidade volumétrica do solo no início do processo de saturação $\left(\theta_{i}\right)$, umidade volumétrica do solo saturado $\left(\theta_{s}\right)$ e condutividade hidráulica do solo saturado $\left(K_{s}\right)$. Utilizou-se para este estudo os valores referentes a camada de 0 - $10 \mathrm{~cm}$ de profundidade, conforme a Tabela 1.

Para a obtenção dos dados de infiltração acumulada no solo, foi utilizado o método de infiltrômetro de anéis, que consiste em utilizar dois anéis metálicos concêntricos, sendo o anel externo com diâmetro de $35 \mathrm{~cm}$ e o interno com $20 \mathrm{~cm}$. Segundo dos Santos Brandão et al. (2006), o anel externo tem como finalidade reduzir o efeito da dispersão lateral da água infiltrada do anel interno. Assim, a água do anel interno infiltra no perfil do solo em direção predominantemente vertical, o que evita a superestimativa da taxa de infiltração.

O procedimento foi executado em dois infiltrômetros simultaneamente, com o auxílio de um equipamento semelhante ao descrito por Lanzanova (2005), que consiste em um cano de PVC, de $150 \mathrm{~mm}$ de diâmetro, com um registro de esfera de $1 / 2$ polegada em ambas as extremidades, contendo água em quantidade conhecida por meio de uma mangueira transparente e uma escala graduada em intervalos de $10 \mathrm{ml}$, suspensos por meio de um tripé de ferro. $\mathrm{O}$ uso deste equipamento facilita as leituras da infiltração e resolve o problema de reposição de água nos casos em que isto é necessário.

Durante a realização do procedimento, registrou-se em forma de tabela os valores da infiltração acumulada, 
Tabela 1: Resultados das análises físicas do solo utilizado no experimento

\begin{tabular}{|c|c|c|c|c|c|c|c|c|}
\hline \multirow{2}{*}{$\begin{array}{l}\text { Prof. } \\
(\mathrm{cm})\end{array}$} & \multicolumn{3}{|c|}{ Granulometria $\left(\mathrm{g} \mathrm{kg}^{-1}\right)$} & \multirow{2}{*}{$\begin{array}{c}\theta_{i} \\
\left(\mathrm{~cm}^{3} \mathrm{~cm}^{-3}\right) \\
\end{array}$} & \multirow{2}{*}{$\begin{array}{c}\theta_{s} \\
\left(\mathrm{~cm}^{3} \mathrm{~cm}^{-3}\right)\end{array}$} & \multirow{2}{*}{$\begin{array}{c}\phi \\
(\%)\end{array}$} & \multirow{2}{*}{$\begin{array}{c}\phi_{\text {macro }} \\
(\%) \\
\end{array}$} & \multirow{2}{*}{$\begin{array}{c}K_{s} \\
\left(m m h^{-1}\right)\end{array}$} \\
\hline & Areia & Silte & Argila & & & & & \\
\hline $0-10$ & 237 & 616 & 147 & 0,23 & 0,80 & 0,46 & 0,39 & 7,70 \\
\hline
\end{tabular}

que foram obtidos através da conversão da altura que constava na régua graduada nos seguintes tempos em minutos: $0,5,10,15,20,25,30,45,60,75,90,105,120,135$, 150, 165, 180. A diferença de leitura entre dois intervalos de tempo representa a infiltração $(I)$ no sentido vertical naquele período, que será utilizado como dado de entrada nos ajustes de curvas e servirá de referência para fins de validação estatística dos modelos.

Tabela 2: Valores da infiltração acumulada em relação ao tempo nos dois infiltrômetros utilizados no experimento

\begin{tabular}{ccc}
\hline & \multicolumn{2}{c}{ Infiltração Acumulada (mm) } \\
\cline { 2 - 3 } Tempo (min) & Infiltrômetro A & Infiltrômetro B \\
\hline 0 & - & - \\
5 & 0 & 1 \\
10 & 0 & 2 \\
15 & 0 & 2 \\
20 & 1 & 2 \\
25 & 1 & 2 \\
30 & 1 & 2 \\
45 & 2 & 3 \\
60 & 3 & 3 \\
75 & 4 & 4 \\
90 & 7 & 4 \\
105 & 9 & 5 \\
120 & 9 & 5 \\
135 & 10 & 5 \\
150 & 10 & 5 \\
165 & 10 & 5 \\
180 & 11,5 & 5 \\
\hline
\end{tabular}

Para o desenvolvimento do trabalho, utilizou-se o modelo de Green-Ampt, pois segundo Cecílio (2005), dentre os modelos existentes para descrever o processo de infiltração, um dos mais bem embasados fisicamente e, portanto mais utilizado é o de Green-Ampt.

$$
\frac{d I(t)}{d t}=K_{s}\left(1+\frac{\psi_{f}\left(\theta_{s}-\theta_{i}\right)}{I}\right)
$$

Onde:

$\psi_{f}=$ potencial matricial do solo na frente de umedecimento $(\mathrm{mm})$

$K_{s}=$ condutividade hidráulica do solo saturado $\left(m m h^{-1}\right)$ $\theta_{s}=$ umidade volumétrica do solo no saturado $\left(\mathrm{cm}^{3} \mathrm{~cm}^{-3}\right)$

$\theta_{i}=$ umidade volumétrica do solo no início do processo de saturação $\left(\mathrm{cm}^{3} \mathrm{~cm}^{-3}\right)$

Para a aplicação do modelo de Green-Ampt, os parâmetros $K_{s}, \psi_{f}, \theta_{s}$ e $\theta_{i}$ devem ser estimados. Entretanto, segundo Rodrigues (1999), a variável $\psi_{f}$ é a mais difícil de ser estimada com precisão, devido a desuniformidade da umidade do solo no início do processo de infiltração e à variação de suas propriedades físicas ao longo do perfil.

Além disso, para Philip (1958), o valor a ser utilizado como $\psi_{f}$ é muito menor que o valor do potencial matricial do solo na frente de umedecimento. Assim sendo, diversos pesquisadores, visando melhorar a estimativa da infiltração sugeriram alternativas para o cálculo do $\psi_{f}$.

Devido a diversidade de propostas para o cálculo do potencial matricial na frente de umedecimento, utilizouse somente os modelos matemáticos recomendados segundo análises feitas por Ataíde (2005), que relacionam o valor do potencial matricial na frente de umedecimento com as características físicas e a condutividade hidráulica do solo saturado.

$$
\begin{aligned}
& \psi_{f}=-1151,78+3122,53 \phi-4,27 K_{s}+1767,23 S \\
& \psi_{f}=267,51-3,39 K_{s}+2049,38 S \\
& \psi_{f}=1040,66-7,10 K_{s}-1953 \phi_{\text {macro }} \\
& \psi_{f}=1066,85-7,73 K_{s}-591,53 \mathrm{~A}
\end{aligned}
$$

Onde:

$\psi_{f}=$ potencial matricial do solo na frente de umedecimento $(\mathrm{mm})$

$K_{s}=$ condutividade hidráulica do solo saturado $\left(m m h^{-1}\right)$

$\phi=$ porosidade total $(\%)$

$\phi_{\text {macro }}=$ macroporosidade $(\%)$

$\mathrm{S}=$ porcentagem de silte $(\%)$

$\mathrm{A}=$ porcentagem de areia $(\%)$

\section{Resultados e Discussões}

Os ajustes do parâmetro do potencial matricial na frente de umedecimento $\left(\psi_{f}\right)$ não foram considerados adequa- 
dos para o tipo de solo estudado, uma vez que, os resultados encontrados extrapolaram o valor da infiltração acumulada condizente com a realidade, conforme é possível observar na Figura 2.

O modelo de Green-Ampt foi aplicado utilizando somente estimativas do valor de $\psi_{f}$, entretanto, grande parte dos autores recomendam também ajustes nos parâmetros de $K_{s}$ e $\theta_{s}$, a fim de buscar uma maior aproximação do modelo com a realidade. Além disso, para a modelagem das propostas do valor de $\psi_{f}$, Ataíde (2005) utilizou três tipos de solos brasileiros: Latossolo Vermelho-Amarelo, Latossolo Vermelho e Argissolo Vermelho.

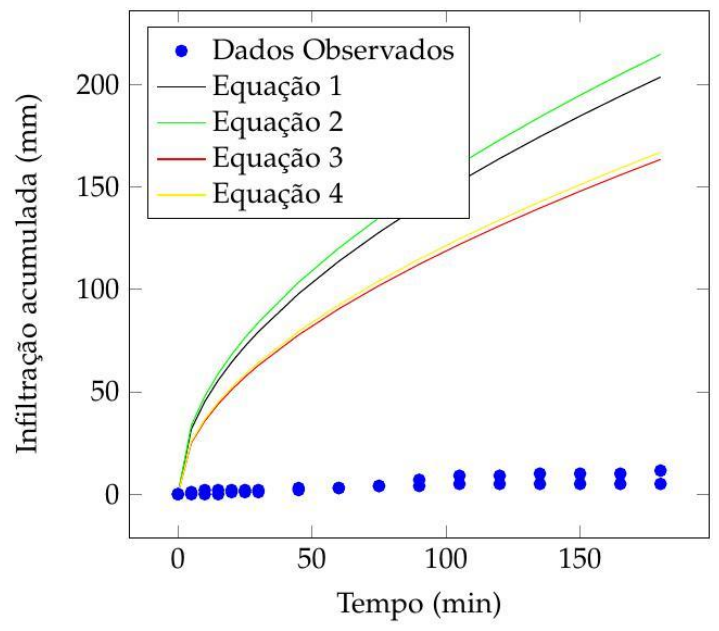

Figura 2: Gráfico dos dados observados nos dois infiltrômetros juntamente com as estimativas obtidas através do ajuste do potencial matricial na frente de umedecimento, utilizando as Equações 1, 2, 3 e 4

Entretanto, os solos hidromórficos em geral, apresentam densidade naturalmente elevada, relação micro/macroporos muito alta e baixa capacidade de armazenamento de água na camada superficial e drenagem natural deficiente (da Silva Gomes e Pauletto, 1999). Esses fatores, associados com os efeitos causados pelo manejo, resultam em características físicas muito diferentes dos solos utilizados por Ataíde (2005) para a formulação de seus modelos, inviabilizando a obtenção de resultados satisfatórios na aplicação dos ajustes propostos para o tipo de solo estudado neste trabalho.

\section{Conclusão}

Com as modificações realizadas utilizando dados do solo para a estimativa do potencial matricial na frente de umedecimento, não foi possível obter bons resultados com o modelo de Green-Ampt no tipo de solo estudado, diferentemente de trabalhos que apresentaram bons resultados, porém para outros tipos de solo.

\section{Referências}

Ataíde, W. F. (2005). Modelagem do potencial matricial na frente de umedecimento. Tese de Doutorado, Universidade Federal de Viçosa, Viçosa.

Buriol, G. A. (2009). Água e Educação: princípios e estratégias de uso e conservação, Centro Universitário Franciscano, Santa Maria, Cap. 4, pp. 109-136.

Cecílio, R. A. (2005). Modelagem da infiltração da água no solo fundamentada na equação de green-amptmein-larson. Tese de Doutorado, Universidade Federal de Viçosa, Viçosa.

EMBRAPA (1999). Sistema Brasileiro de Classificação de Solo. EMBRAPA.

Lanzanova, M. E. (2005). Atributos físicos do solo em sistemas de culturas sob plantio direto na integração lavoura-pecuária. Dissertação de Mestrado, Universidade Federal de Santa Maria, Santa Maria.

de Mello, L. T. A. (2003). Avaliação de metodologias para obtenção dos parâmetros do modelo de green-ampt modificado por mein e larson. Tese de Doutorado, Universidade Federal de Viçosa, Viçosa.

Philip, J. (1958). The theory of infiltration: 7. Soil Science, 85(6), 333-337.

Reichardt, K., Timm, L. C. (2004). Solo, planta e atmosfera: conceitos, processos e aplicações, $2^{\circ}$ edn. Manole, Barueri.

Rodrigues, L. N. (1999). Modelo para dimensionamento e para simulação do desempenho de pivô central. Tese de Doutorado, Universidade Federal de Viçosa.

dos Santos Brandão, V., Cecílio, R. A., Pruski, F. F., da Silva, D. D. (2006). Infiltração da água no solo, $3^{\circ}$ edn. UFV, Viçosa.

da Silva Gomes, A., Pauletto, E. A. (1999). Manejo de solo e da água em áreas de várzea, $1^{\circ}$ edn. Embrapa Clima Temperado, Pelotas. 